\title{
Correction to: Implicit Cognition Tests for the Assessment of Suicide Risk: a Systematic Review
}

\author{
Manon Moreno ${ }^{1,2} \cdot$ Luis Gutiérrez-Rojas $^{3,4} \cdot$ Alejandro Porras-Segovia ${ }^{1,4,5}$
}

Published online: 5 March 2022

(c) The Author(s), under exclusive licence to Springer Science+Business Media, LLC, part of Springer Nature 2022

\section{Correction to: Current Psychiatry Reports https://doi.org/10.1007/s11920-022-01316-5}

The original version of this article unfortunately contained a mistake. The name of our co-author should be corrected to 'Luis Gutiérrez-Rojas'.

The original article has been corrected.

Publisher's Note Springer Nature remains neutral with regard to jurisdictional claims in published maps and institutional affiliations.

The original article can be found online at https://doi.org/10.1007/ s11920-022-01316-5.

Manon Moreno

manon8410@gmail.com

1 Instituto de Investigación Sanitaria Fundación Jiménez Díaz, Madrid, Spain

2 Universidad Autónoma de Madrid, Madrid, Spain

3 Department of Psychiatry, Hospital Universitario Clínico San Cecilio, Granada, Spain

4 Department of Psychiatry, School of Medicine, Universidad de Granada, Granada, Spain

5 Department of Psychiatry, Hospital Universitario Rey Juan Carlos, Móstoles, Spain 